\title{
Author Correction: Mining
} of efficient microbial UDP. glycosyltransferases by motif evolution cross plant kingdom for application in biosynthesis of
salidroside

\author{
Bo Fan ${ }^{1}$, Tianyi Chen ${ }^{1}$, Sen Zhang ${ }^{4}$, Bin Wu ${ }^{1,3}$ \& Bingfang He $\mathrm{He}^{1,2,3}$ \\ Scientific Reports 7:463; doi:10.1038/s41598-017-00568-Z; Article published online 28 March 2017
}

This Article contains an error in Table 2 where the Glycosylation Products distribution percentages for 3-phenolic glucoside and $4^{\prime}$-phenolic glucoside have been inverted and should read $13 \%$ for 3 -phenolic glucoside and $87 \%$ for $4^{\prime}$-phenolic glucoside.

(i) Open Access This article is licensed under a Creative Commons Attribution 4.0 International License, which permits use, sharing, adaptation, distribution and reproduction in any medium or format, as long as you give appropriate credit to the original author(s) and the source, provide a link to the Creative Commons license, and indicate if changes were made. The images or other third party material in this article are included in the article's Creative Commons license, unless indicated otherwise in a credit line to the material. If material is not included in the article's Creative Commons license and your intended use is not permitted by statutory regulation or exceeds the permitted use, you will need to obtain permission directly from the copyright holder. To view a copy of this license, visit http://creativecommons.org/licenses/by/4.0/.

(C) The Author(s) 2017

\footnotetext{
${ }^{1}$ College of Biotechnology and Pharmaceutical Engineering, Nanjing Tech University, 30 Puzhunan Road, 211816, Nanjing, China. ${ }^{2}$ School of pharmaceutical sciences, Nanjing Tech University, 30 Puzhunan Road, 211816, Nanjing, China. ${ }^{3}$ Jiangsu National Synergetic Innovation Center for Advanced Materials, 30 Puzhunan road, Nanjing, 211816, Jiangsu, China. ${ }^{4}$ Jiangsu Collaboration Innovation Center of Chinese Medical Resources Industrialization, Nanjing University of Chinese Medicine, 138 Xianlin Road, 210023, Nanjing, China. Correspondence and requests for materials should be addressed to B.H. (email: bingfanghe@njtech.edu.cn)
} 